\title{
Effect of pertussis toxin on calcium influx in three contraction models
}

\author{
ELŻBIETA GRZEŚK ${ }^{1}$, BARBARA TEJZA ${ }^{1}$, MICHAŁ WICIŃSKI ${ }^{2}$, BARTOSZ MALINOWSKI $^{2}$, \\ KATARZYNA SZADUJKIS-SZADURSKA ${ }^{2}$, LILIANNA BARAN ${ }^{2}$, ELŻBIETA KOWAL ${ }^{2}$ and GRZEGORZ GRZEŚK ${ }^{2}$ \\ Departments of ${ }^{1}$ Pediatrics, Hematology and Oncology and ${ }^{2}$ Pharmacology and Therapeutics, \\ Collegium Medicum, Nicolaus Copernicus University, Bydgoszcz 85094, Poland
}

Received February 23, 2014; Accepted April 30, 2014

DOI: $10.3892 /$ br.2014.274

\begin{abstract}
Pertussis toxin (PTX) blocks G protein activation and inhibits signal transmission from the activated receptor to effectors that are specific for the $\mathrm{G}$ protein-coupled receptor. The aim of the present study was to evaluate the effect of PTX on vascular smooth muscle cells that were stimulated pharmacologically with phenylephrine ( $\alpha$-adrenoceptor agonist), mastoparan-7 (direct G-protein activator) and Bay K8644 (direct calcium channel activator). The changes in perfusion pressure that were proportional to the degree of phenylephrine-induced constriction of rat tail arteries were assessed. Concentration-response curves (CRCs) that were obtained for phenylephrine, mastoparan-7 and Bay K8644 presented a sigmoidal association. A significantly reduced calcium influx to the cytoplasm in the presence of mastoparan-7 resulted in a significant rightward shift of the CRCs with a significant reduction in maximal responses. The presence of PTX did not change mastoparan-7 and Bay K8644-induced contraction, whereas the significant inhibition of phenylephrine-induced contraction was found. The results of the experiments indicated that PTX significantly inhibited phenylephrine-induced contraction of vascular smooth muscle cells by inhibition of calcium influx from the intra- and extracellular calcium space. PTX did not change the smooth muscle contraction that was induced by mastoparan-7 and Bay K8644. The predominant effect of mastoparan-7 may be associated with other binding sites as compared to the G-protein or PTX may bind to other sites than mastoparan-7.
\end{abstract}

Correspondence to: Dr Elżbieta Grześk, Department of Pediatrics, Hematology and Oncology, Collegium Medicum,Nicolaus Copernicus University, 9 Skłodowskiej-Curie Street, Bydgoszcz 85094, Poland E-mail: ellag@cm.umk.pl

Abbreviations: $\mathrm{CRC}$, concentration response curve; $\mathrm{EC}_{50}$, half maximal effect concentration; $\mathrm{E}_{\max }$, maximal tissue response; mas-7, mastoparan-7; PLC, phospholipase C; PTX, pertussis toxin

Key words: pertussis toxin, mastoparan-7, Bay K8644, G protein

\section{Introduction}

Pertussis toxin (PTX) was first described in 1979 following the report of the PTX-induced stimulation mechanism of insulin release from pancreatic islets in rats (1). The mechanism of PTX action is associated with the inhibition of G protein activation, and thus PTX inhibits the signal transmission from the activated receptor to the effectors that are specific for the $\mathrm{G}$ protein-coupled receptor. The inhibitory effect is secondary to adenoside diphosphate-ribosylation of the $\alpha$-subunit of the G protein (2). Currently, PTX toxin is commonly used in numerous experimental models of signaling pathways.

Mastoparan-7 demonstrates an inhibitory mechanism of action on $\mathrm{G}$ protein, mimicking the action of the active receptor binding to its $\mathrm{G}$ protein. Additionally, in certain cell types interactions with phospholipase C (PLC) have been found. Stimulation of PLC has been described previously (3) for rat mast cells and hepatocytes and human HL-60 leukaemia cells, whereas inhibition of PLC has been found for SH-SY5Y human neuro-blastoma cells and human astrocytoma cells (3). Results of recent studies have indicated that there is a possibility of stimulation of programmable cell death in various types of cells (4-6).

Calcium ions play a regulatory role in cell life, but prolonged high concentrations may induce apoptosis, which leads to cell death. Cell stimulation induces an increase in calcium influx into the cytoplasm primarily from intracellular calcium stores and secondarily resulting in binding to structures, including calpain and calcineurin. Calpain belongs to the cysteine proteases family that activates Bid and Bax and promotes their transport to the mitochondria. An excess of $\mathrm{Ca}^{2+}$ in mitochondria also leads to the release of proapoptotic proteins that are located in the intracellular space; Smac/DIABLO and cytochrome $c(7,8)$. The results of our previous study indicated that PTX, as a G-protein inhibitor, is not able to inhibit contraction induced by direct stimulation of G-protein by mastoparan-7 (9).

The aim of the present study was to evaluate the effect of PTX on vascular smooth muscle cells that were stimulated pharmacologically with phenylephrine ( $\alpha$-adrenoceptor agonist), mastoparan-7 (direct G-protein activator) and Bay K8644 (direct calcium channel activator). 


\section{Materials and methods}

Animals. Experiments were performed on isolated and perfused tail arteries of Wistar rats (weight, 250-270 g). The animals were housed under a 12-h light/dark cycle and had unlimited access to food and water. The rats were narcotized by intraperitoneal injection of $120 \mathrm{mg} / \mathrm{kg}$ urethane and then sacrificed by stunning and cervical dislocation. The study protocol was approved by the Local Ethics Committee. All the studies were carried out in accordance with the United States NIH guidelines [Guide for the Care and Use of Laboratory Animals (1985), DHEW Publication No. (NIH) 85-23; Office of Science and Health Reports, DRR/NIH, Bethesda, MD, USA].

Drugs and solutions. Krebs solution contained $\mathrm{NaCl}$ (71.8 mM/l), $\mathrm{KCl}(4.7 \mathrm{mM} / 1), \mathrm{CaCl}_{2}(1.7 \mathrm{mM} / 1) \mathrm{NaHCO}_{3}$ (28.4 mM/l), $\mathrm{MgSO}_{4}(2.4 \mathrm{mM} / \mathrm{l}), \mathrm{KH}_{2} \mathrm{PO}_{4}(1.2 \mathrm{mM} / \mathrm{l})$ and glucose $(11.1 \mathrm{mM} / \mathrm{l})$. All the reagents were purchased from Sigma-Aldrich (St. Louis, MO, USA).

Study design and conduction. Following dissection from the surrounding tissues, a $2-3-\mathrm{cm}$ long segment of a rat tail artery was cannulated and connected to a perfusion device. The distal part was weighed with a $500 \mathrm{mg}$ weight and the tail was placed in a $20-\mathrm{ml}$ container filled with oxygenated Krebs solution at $37^{\circ} \mathrm{C}(\mathrm{pH} 7.4)$. The samples were prepared in the presence of PTX $(100 \mathrm{ng} / \mathrm{ml})$ and were incubated in oxygenated Krebs solution for $24 \mathrm{~h}$. The perfusion pressure was continuously measured. The perfusion solution flow was gradually increased using a peristaltic pump to $1 \mathrm{ml} / \mathrm{min}$, until the optimum perfusion pressure of $2-4 \mathrm{kPa}$ was reached $(10,11)$.

Data analysis and statistical procedures. The investigations were performed on a TSZ-04 system from Experimetria Ltd. (Budapest, Hungary). The perfusion pressure was measured on BPR-01 and BPR-02 devices, and the vascular smooth muscle tension was measured on a FSG-01 transducer connected with a digital recorder Graphtec GL820 midi Logger. All transducers used in the experiments were made by Experimetria Ltd., and the peristaltic pump was made by Zalimp (Warsaw, Poland).

Concentration-response curves (CRCs) were calculated according to the van Rossum method. The maximum response of tissues $\left(E_{\max }\right)$ was calculated as a percentage of maximal response for phenylephrine. The half maximal effective concentration $\left(\mathrm{EC}_{50}\right)$ was estimated using classical pharmacological methods with $\mathrm{pD}_{2}$, the negative logarithm of the $\mathrm{EC}_{50}$. The number of the $\mathrm{CRC}$ and $\mathrm{E}_{\max }$ was used in all calculations to estimate the statistical significance. Mastoparan-17 was used as a negative control.

The results were presented as mean \pm standard deviation. Statistical analysis was performed using the analysis of variance test for multiple comparison of the means. $\mathrm{P}<0.05$ was considered to indicate a statistically significant difference.

\section{Results}

The CRC obtained for phenylephrine, mastoparan-7 and Bay K8644 presented a sigmoidal association. The curve obtained for phenylephrine in the presence of PTX was significantly shifted to the right (all values of relative effect

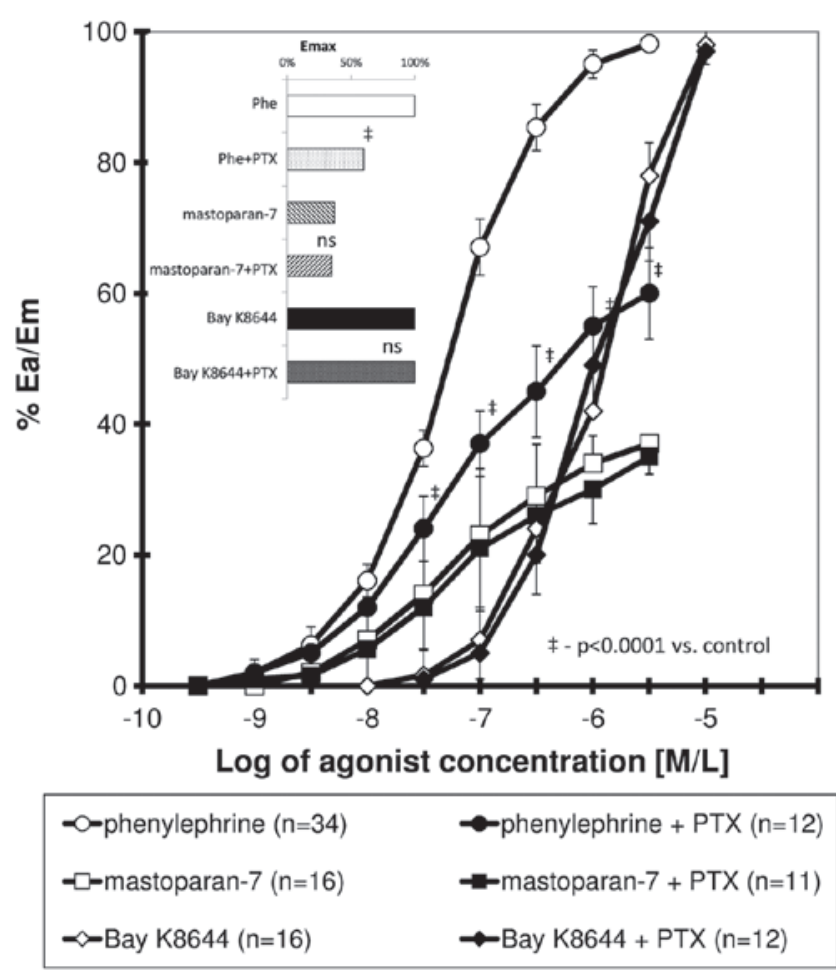

Figure 1. Concentration response curves for phenylephrine (Phe), mastoparan-7 and Bay K8644 in the control and in the presence of pertussis toxin (+PTX). $\mathrm{E}_{\max }$, maximal tissue response; ns, not significant.

from 20 to $100 \%$ ) with a significant reduction in maximal response, whereas PTX did not significantly modify the CRCs for mastoparan-7 and Bay K8644 (Fig. 1). Table I shows the calculated pharmacometric date, including $\mathrm{E}_{\max }, \mathrm{EC}_{50}$ and $\mathrm{pD}_{2}$.

In the presence of PTX, a significant reduction in the calcium influx that was induced by phenyleprine from the intra- and extracellular space was found. For the two phases of contraction, mastoparan-7 induced a significant increase of the perfusion pressure in comparison to its negative control, mastoparan-17. PTX did not change the calcium influx that was induced by mastoparan-7 and did not modify the influx from the extracellular calcium space (phase 2 only) that was induced by Bay K8644 (Fig. 2, Table II).

\section{Discussion}

In the present study, the effect of PTX on arterial contraction induced in three contraction models was compared, including the activation of the $\alpha 1$-adrenoceptor with its selective agonist phenylephrine, the direct activation of G-protein with mastoparan-7 and the direct activation of the L-type calcium channel with Bay K8644. Stimulation with phenylephrine or Bay K8644 resulted in a rapid increase in the perfusion pressure and the maximal responses were achieved in seconds, whereas mastoparan-7-induced contraction required significantly more time; typically the maximal result was observed after 30-40 min of incubation. Additionally, no influence was observed of PTX on contraction induced by the adrenoceptor stimulation pathway elements located on and below the $\mathrm{G}$ protein, including mastoparan-7 or Bay K8644. 
Table I. $\mathrm{EC}_{50}$, maximal response and relative potency for phenylephrine, mastoparan-7 and Bay K8644 for controls and in the presence of pertussis toxin $(+\mathrm{PTX})$.

\begin{tabular}{lccccc}
\hline Compound & $\mathrm{n}^{\mathrm{a}}$ & $\mathrm{E}_{\max }^{\mathrm{b}}, \%$ & $\mathrm{EC}_{50}(\mathrm{M} / \mathrm{l})$ & $\mathrm{pD}_{2}$ & $\mathrm{RP}^{\mathrm{c}}$ \\
\hline Phenylephrine & 34 & 100 & $7.51( \pm 0.97) \times 10^{-8}$ & $7.13 \pm 0,06$ & - \\
Phenylephrine + PTX & 12 & $60 \pm 7$ & $1.16( \pm 0.85) \times 10^{-7}$ & $6.93 \pm 0,05$ & 0.647 \\
Mastoparan-7 & 16 & $37 \pm 4$ & $4.41( \pm 2.33) \times 10^{-8}$ & $7.40 \pm 0.20$ & - \\
Mastoparan-7 + PTX & 11 & $35 \pm 4$ & $6.12( \pm 3.40) \times 10^{-8}$ & $7.21 \pm 0.22$ & 0.721 \\
Bay K8644 & 16 & 100 & $1.97( \pm 0.24) \times 10^{-6}$ & $5,71 \pm 0,05$ & - \\
Bay K8644 + PTX & 12 & $97 \pm 2$ & $2.42( \pm 0.45) \times 10^{-6}$ & $5.61 \pm 0,09$ & 0.1593 \\
\hline
\end{tabular}

${ }^{a}$ Number of concentration-response curves used for calculations; ${ }^{b} \mathrm{E}_{\max }$ calculated as a percentage of maximal response for controls, $\% \mathrm{E}_{\max }$ values for mastoparan-7 were calculated in comparison to control-concentration response curves for phenylephrine; 'relative potency, calculated as $\mathrm{EC}_{50}$ for controls/EC $\mathrm{E}_{50}$; ${ }^{\mathrm{d}} \mathrm{P}$-value calculated in comparison to control values. $\mathrm{EC}_{50}$, half maximal effect concentration; $\mathrm{E}_{\max }$, maximal tissue response; $\mathrm{pD}_{2}$, negative logarithm of the $\mathrm{EC}_{50}$.

Table II. Maximal perfusion pressure for phenylephrine, mastoparan-7 and Bay K8644-induced contraction activated by calcium influx from intracellular (phase 1) and extracellular calcium stores (phase 2), for controls and in the presence of pertussis toxin (+PTX).

\begin{tabular}{lcccc}
\hline & \multicolumn{2}{c}{ Intracellular calcium phase 1} & \multicolumn{2}{c}{ Extracellular calcium phase 2 } \\
\cline { 3 - 4 } Compound & $\mathrm{n}$ & Perfusion pressure $( \pm$ SD $)$, mmHg & $\mathrm{n}$ & Perfusion pressure $( \pm$ SD $)$, mmHg \\
\hline Phenylephrine & 30 & $57.9( \pm 6.2)$ & 30 & $93.6( \pm 6.1)$ \\
Phenylephrine + PTX & 32 & $23.8( \pm 4.4)^{\mathrm{a}}$ & 32 & $43.4( \pm 3.8)^{\mathrm{a}}$ \\
Mastoparan-17 & 10 & $11.8( \pm 2.1)$ & 10 & $10.1( \pm 2.4)$ \\
Mastoparan-7 & 16 & $17.4( \pm 3.1)$ & 16 & $28.3( \pm 5.6)$ \\
Mastoparan-7 + PTX & 11 & $18.2( \pm 4.7)$ & 11 & $27.4( \pm 8.5)$ \\
Bay K8644 & 16 & $15.4( \pm 4.0)$ & 16 & $75.3( \pm 4.5)$ \\
Bay K8644 + PTX & 12 & $12.4( \pm 6.4)$ & 12 & $76.2( \pm 6.0)$ \\
\hline
\end{tabular}

${ }^{\mathrm{a}} \mathrm{P}<0.0001$ vs. control. SD, standard deviation.

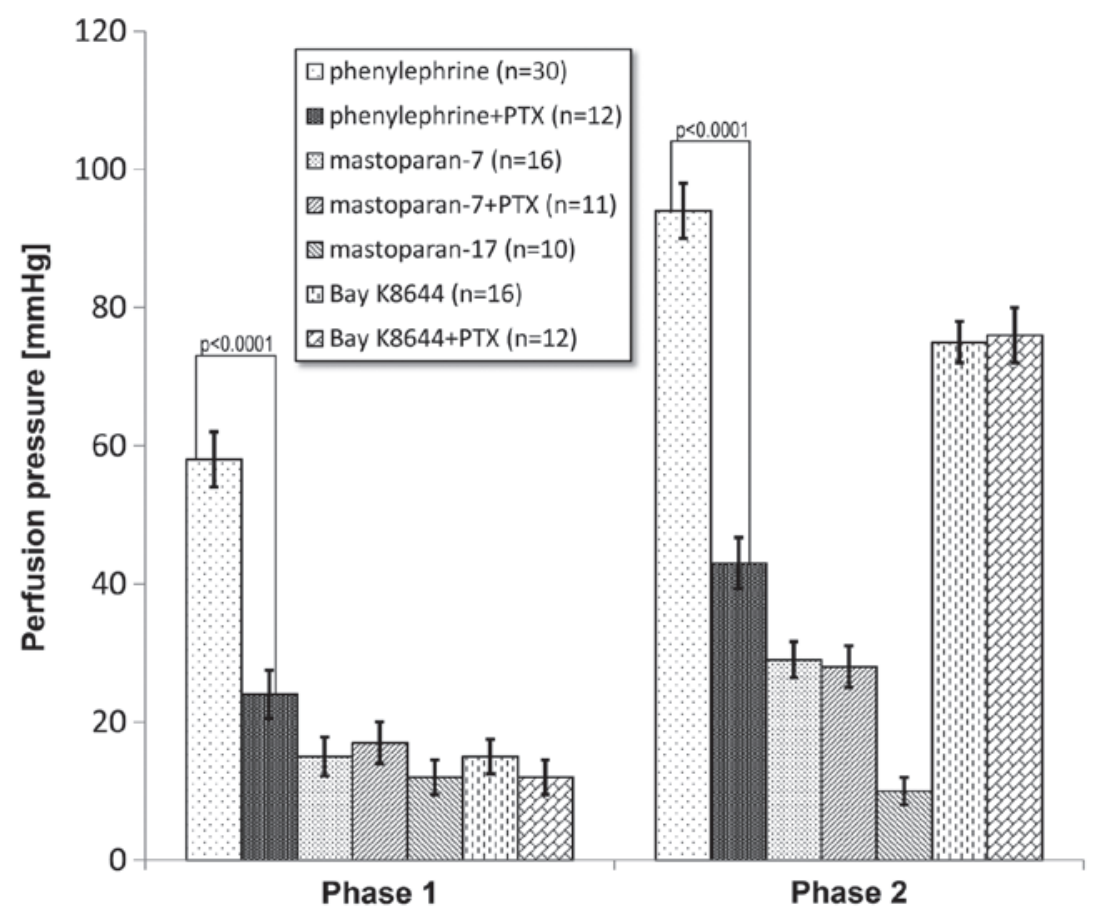

Figure 2. Impact of pertussis toxin (PTX) on perfusion pressure, triggered by the intra- and extracellular calcium pool in comparison to the controls. 
PTX consists of two subunits. The first is A-protomer, which ribosylates the $\alpha$-subunits of heterotrimeric G (i/o) proteins, thus inhibiting the possibility of binding between the active receptor and its $\mathrm{G}$ protein. The second subunit, B-oligomer, may induce an intracellular signal transduction cascade by binding to various active proteins located on the cell surface. This is how PTX may modulate the cell by two different, partially independent pathways (12).

In the experiment performed on the spiral fragments of common carotid arteries, the response to mastoparan-7 was not altered in the presence of PTX and the phospholipase A2 inhibitor, indomethacin. The L-type calcium channel blockade with nifedipine inhibited contractility induced by mastoparan-7. The study indicated that the lack of reversal by nifedypine at higher concentrations of mastoparan-7 may suggest the activation of others than just the $G$ protein targets during the action of mastoparan-7 (13).

$\mathrm{G}$ protein is the cornerstone in the activation of different metabotropic receptors, including $\alpha$-adrenergic receptors, vasopressin receptors (V1) or angiotensin II receptors, type 1. As the subsequent element in $G$ protein-coupled receptor activation the enzyme is regulated, thereby identifying phospholipase C (PLC) (14-16).

Mastoparan-7 penetrates through biological barriers and binds to the $\mathrm{G}$ protein binding site ligand receptor and stimulates $\mathrm{G}$ protein in an analogical way by activating the receptor. Results of a previous biochemical study indicate that the affinity of mastoparam-7 to various G-proteins differs significantly and is higher for $G_{i}$ and $G_{s}$ in comparison to $G_{q}(17)$. This is the reason for PTX not modifying the $\mathrm{G}_{\mathrm{q} 11}$-dependent contraction of vascular smooth muscle cells following mastoparan-7 stimulation (11). The L-type calcium channel blockers inhibit the calcium influx from extracellular calcium stores only and are able to inhibit this process which is present following the stimulation of the $\mathrm{G}$ protein-coupled receptor, mastoparan-7 and Bay K8644 (10,13,18,19).

Direct stimulation of the L-type calcium channel with Bay K8644 in the present study induced a significant smooth muscle contraction, while the presence of PTX did not inhibit this process. The mechanism of mastoparan-7 action is not clear. Mastoparan-7 may also induce vascular smooth muscle contraction, not only by G-protein activation, but also by modulation and voltage-independent calcium channels (18), inhibition of PLC in low concentration $\left(<3 \times 10^{-6} \mathrm{M} / \mathrm{l}\right)$ or activation in high concentrations $\left(>5 \times 10^{-6} \mathrm{M} / \mathrm{l}\right)(21,22)$. Contraction in the models was induced at a concentration range from $3 \times 10^{-10}$ to $3 \times 10^{-6} \mathrm{M} / 1$, and thus the additional inhibition of PLC may be confused with contraction. In view of this, the concentrations used were not sufficiently increased to alter, other than the G-protein elements of the signaling pathway. Contraction in the presence of phenylephrine and mastoparan-7 was induced by calcium influx from intra- and extracellular calcium stores, whereas in the presence of Bay K8644 it was associated with the calcium influx from extracellular calcium stores only. The inhibition of phenylephrine-induced contraction and no inhibition in Bay K8644-induced contraction appears to be clear. However, no change in mastoparan-7-induced contractility may be the result of various binding places on the G-protein or the activation of sites other than the G-protein binding places.
In conclusion, the results of the study have shown that PTX significantly inhibited the phenylephrine-induced contraction of vascular smooth muscle cells by inhibition of the calcium influx from intra- and extracellular calcium space. PTX did not change the smooth muscle contraction induced by mastoparan-7 and Bay K8644. The predominant effect of mastoparan-7 may be associated with sites other than the G-protein binding sites or PTX binds to other sites than that of mastoparan-7.

\section{References}

1. Katada T: The inhibitory G protein G(i) identified as pertussis toxin-catalyzed ADP-ribosylation. Biol Pharm Bull 35: 2103-2111, 2012.

2. Sowa NA, Street SE, Vihko P and Zylka MJ: Prostatic acid phosphatase reduces thermal sensitivity and chronic pain sensitization by depleting phosphatidylinositol 4,5-bisphosphate. J Neurosci 30: 10282-10293, 2010.

3. King TP, Jim SY and Wittkowski KM: Inflammatory role of two venom components of yellow jackets (Vespula vulgaris): a mast cell degranulating peptide mastoparan and phospholipase A1. Int Arch Allergy Immunol 131: 25-32, 2003.

4. Hoshina MM, Santos LD, Palma MS and Marin-Morales MA: Cytotoxic, genotoxic/antigenotoxic and mutagenic/antimutagenic effects of the venom of the wasp Polybia paulista. Toxicon 72 , 64-70, 2013.

5. Yordanova ZP, Woltering EJ, Kapchina-Toteva VM and Iakimova ET: Mastoparan-induced programmed cell death in the unicellular alga Chlamydomonas reinhardtii. Ann Bot 111: 191-205, 2013.

6. Lin CH, Hou RF, Shyu CL, Shia WY, Lin CF and Tu WC: In vitro activity of mastoparan-AF alone and in combination with clinically used antibiotics against multiple-antibiotic-resistant Escherichia coli isolates from animals. Peptides 36: 114-120, 2012.

7. Hajnóczky G, Davies E and Madesh M: Calcium signaling and apoptosis. Biochem Biophys Res Commun 304: 445-454, 2003.

8. Newmeyer DD and Ferguson-Miller S: Mitochondria: releasing power for life and unleashing the machineries of death. Cell 112: 481-390, 2003.

9. Grześk G, Malinowski B, Grześk E, Wiciński M and Szadujkis-Szadurska K: Direct regulation of vascular smooth muscle contraction by mastoparan-7. Biomed Rep 2: 34-38, 2014.

10. Grześk G, Wiciński M, Malinowski B, Grześk E, Manysiak S, Odrowąż-Sypniewska G, Darvish N and Bierwagen M: Calcium blockers inhibits cyclosporine A-induced hyperreactivity of vascular smooth muscle cells. Mol Med Rep 5: 1469-1474, 2012.

11. Grzesk G, Kozinski M, Navarese EP, Krzyzanowski M, Grzesk E, Kubica A, Siller-Matula JM, Castriota F and Kubica J: Ticagrelor, but not clopidogrel and prasugrel, prevents ADP-induced vascular smooth muscle cell contraction: a placebo-controlled study in rats. Thromb Res 130: 65-69, 2012.

12. Mangmool S and Kurose H: G(i/o) protein-dependent and -independent actions of Pertussis Toxin (PTX). Toxins (Basel) 3: 884-899, 2011.

13. Kanagy NL and Webb RC: Enhanced vascular reactivity to mastoparan, a $\mathrm{G}$ protein activator, in genetically hypertensive rats. Hypertension 23: 946-950, 1994.

14. Birnbaumer L: The discovery of signal transduction by G-proteins: a personal account and an overview of the initial findings and contributions that led to our present understanding. Biochim Biophys Acta 1768: 756-771, 2007.

15. Cotecchia S: The $\alpha 1$-adrenergic receptors: diversity of signaling networks and regulation. J Recept Signal Transduct Res 30: 410-419, 2010.

16. Bylund DB, Bond RA, Clarke DE, et al (eds): The IUPHAR Media Compendium of Receptor Characterization and Classification. 2nd edition. IUPHAR Media, London, 2000.

17. Higashijima T, Burnier J and Ross EM: Regulation of Gi and Go by mastoparan, related amphiphilic peptides, and hydrophobic amines. Mechanism and structural determinants of activity. J Biol Chem 265: 14176-14186, 1990. 
18. Perianin A and Synderman R: Mastoparan, a wasp venom peptide, indentifies two discrete mechanisms of elevating cytosolic calcium and inositol triphosphates in human polymorphonuclear leukocytes. J Immunol 143: 1669-1673, 1989.

19. Dostal DE, Murahashi T and Peach MJ: Regulation of cytosolic calcium by angiotensis in vascular smooth muscle. Hypertension 15: 815-822, 1990.

20. Argiolas A and Pisano JJ: facilitation of phospholipase A2 activity by mastoparan, a new class of mast cell degranulating peptides from wasp venom. J Biol Cchem 258: 13697-13702, 1983.
21. Wallace MA and Carter HR: effects of the wasp venom peptide, mastoparan, on a phosphoinositide-specific phospholipase $\mathrm{C}$ purified from rabbit brain membranes. Biochim Biophys Acta 1006: 311-316, 1989.

22. Hiramatsu Y, Horn VJ, Baum BJ and Ambudkar IS: Characterization of polyphosphoinositide-specific phospholipase $\mathrm{C}$ in rat parotid gland membranes. Arch Biochem Biophys 297: 368-376, 1992. 